\title{
A Phylogenetic Analysis of Borrelia burgdorferi Sensu Lato Isolates Associated with Lyme Disease in Japan by Flagellin Gene Sequence Determination
}

\author{
MASAHITO FUKUNAGA* AND YASUYO KOREKI \\ Faculty of Pharmacy and Pharmaceutical Sciences, Fukuyama University, Fukuyama 729-02, Japan
}

\begin{abstract}
We determined nearly complete flagellin gene sequences for Borrelia burgdorferi sensu lato isolates (11 isolates obtained from Ixodes persulcatus ticks and patients in Hokkaido, Japan, and 1 European isolate) representing six different restriction fragment length polymorphism (RFLP) ribotype groups following cloning of the PCR-amplified genes. These sequences were aligned with those of representatives of the three Borrelia species associated with Lyme disease, and a phylogenetic tree was constructed by the Clustal method. On the Lyme disease borrelia portion of the tree, the species were clearly delineated into three different phylogenetic groups, in complete agreement with the division of $B$. burgdorferi sensu lato into three species. A phylogenetic analysis revealed that the representatives of RFLP ribotype groups IV, V, and VI clustered tightly with each other and belonged on the same branch as Borrelia garinii. We used the criteria that are currently used to delineate bacterial species and determined the levels of DNA relatedness for these Borrelia isolates. For the RFLP ribotype group $I V, V$, and VI isolates, the levels of DNA relatedness ranged from 79 to $88 \%$, and the levels of relatedness to the reference strain of $B$. garinii ranged from 70 to $80 \%$. The levels of DNA relatedness of the RFLP ribotype group IV, V, and VI isolates to the representatives of other species associated with Lyme disease ranged from 53 to $66 \%$. All of these findings indicate that the RFLP ribotype group IV, V, and VI isolates should be included in the species $B$. garinii.
\end{abstract}

The following three validly described Borrelia species are associated with Lyme disease: Borrelia burgdorferi sensu stricto, Borrelia garinii, and Borrelia afzelii $(5,8,21)$. Although the distribution of $B$. burgdorferi sensu stricto is rather restricted in North America and Europe, B. garinii and B. afzelii are widely distributed in all of the north temperate regions of the world except North America. It has been generally assumed that Ixodes ricinus species complex ticks are major vectors for transmitting infections to humans and that the spirochetes are maintained by vector-reservoir transmission cycles involving blood-sucking ticks and wildlife vertebrates $(1,2,6,20)$.

A large number of spirochete strains have been isolated from patients exhibiting erythema migrans, Ixodes persulcatus ticks, and reservoir rodents (Apodemus speciosus) in the northern part of Japan, where Lyme disease is endemic $(4,12,14,22$, $26,28,30)$. Using sodium dodecyl sulfate-polyacrylamide gel electrophoresis analysis, Western blot (immunoblot) analysis with monoclonal antibodies, the restriction fragment length polymorphism (RFLP) ribotyping method, and a 16S rRNA gene-based PCR assay, we have demonstrated that these isolates exhibit considerable phenotypic and genetic heterogeneity $(12,14,32,33)$. No $B$. burgdorferi sensu stricto isolate has been found in the material examined so far in Japan. Some of the isolates were classified as $B$. garinii or $B$. afzelii strains by our typing methods, while the other isolates were apparently not members of any of the three species associated with Lyme disease $(14,30)$. We tentatively classified these organisms as members of ribotype groups IV, V, and VI. RFLP ribotype group IV is the predominant group among isolates derived from clinical specimens, reservoir rodents, and $I$. persulcatus vector ticks in Japan. Therefore, we wanted to determine the

* Corresponding author. Mailing address: Laboratory of Molecular Microbiology, Faculty of Pharmacy and Pharmaceutical Sciences, Fukuyama University, Gakuencho 1, Fukuyama, Hiroshima 729-02, Japan. Phone: 8184936 2111. Fax: 8184936 2024. Electronic mail address: mfukunag@ddbj.nig.ac.jp. taxonomic status of the groups in order to clarify the relationships between them and the three species associated with Lyme disease.

We cloned and sequenced the outer surface protein $\mathrm{C}$ (OspC) gene of unknown Borrelia isolates since the OspC gene was present in all $B$. burgdorferi sensu lato strains, and the sequences exhibited significant diversity (9). Sequence analysis of the $\mathrm{OspC}$ gene and the predicted amino acid alignment were thought to be useful tools for species identification of the spirochete isolates. Actually, alignment of the OspC sequences revealed that the species-specific domain was conserved in all of the ribotype group IV, V, and VI isolates. However, overall OspC sequences were highly variable, and assignment of the isolates to Borrelia species was inconclusive.

In this study we characterized the spirochete isolates mentioned above. As determined by DNA-DNA hybridization experiments, three new RFLP ribotype group isolates were closely related to $B$. garinii strains since the levels of DNA relatedness were more than $70 \%$. A phylogenetic analysis based on flagellin gene sequences clearly revealed that most of the Japanese isolates belong to $B$. garinii. Despite differences in phenotypic and genetic characteristics, we concluded that the spirochetes belonging to unknown species diverged within the species $B$. garinii. Our findings also indicate that flagellin gene sequence analysis is a useful tool for assessing the closely related Borrelia isolates associated with Lyme disease.

\section{MATERIALS AND METHODS}

Bacterial strains and culture conditions. The $B$. burgdorferi sensu lato isolates used in this study are listed in Table 1. The spirochetes were grown in BSKII medium at $31^{\circ} \mathrm{C}$ as described previously (40). Spirochete cells at the late exponential phase $(500 \mathrm{ml}$ of culture) were harvested and washed by centrifugation. Escherichia coli HB101 was used for transformation with a recombinant plasmid.

RFLP ribotyping analysis. Spirochete DNAs were prepared as described previously (10) and were digested with EcoRV or HinclI; they were then electrophoresed in a $1 \%$ agarose gel, stained with ethidium bromide, photographed, and blotted by the method of Southern (39). 23S rRNA gene fragments NP and Sty from $B$. burgdorferi sensu stricto type strain B31 were labeled and used as 
TABLE 1. B. burgdorferi sensu lato strains used in ribotyping and PCR amplification analyses

\begin{tabular}{|c|c|c|c|c|c|c|c|}
\hline \multirow[b]{2}{*}{ Species } & \multirow[b]{2}{*}{ Strain } & \multirow[b]{2}{*}{ Source } & \multirow{2}{*}{$\begin{array}{l}\text { RFLP ribotype } \\
\text { group }\end{array}$} & \multicolumn{4}{|c|}{ PCR amplification } \\
\hline & & & & $\begin{array}{l}\text { Primer } \\
\text { set SC }\end{array}$ & $\begin{array}{l}\text { Primer } \\
\text { set BB }\end{array}$ & $\begin{array}{l}\text { Primer } \\
\text { set BG }\end{array}$ & $\begin{array}{l}\text { Primer } \\
\text { set VS }\end{array}$ \\
\hline \multirow[t]{5}{*}{ B. burgdorferi sensu stricto } & $\mathrm{B} 31^{\mathrm{T}}$ & Ixodes scapularis (United States) & I & + & + & - & - \\
\hline & IPS & Ixodes pacificus (United States) & I & + & + & - & - \\
\hline & 1352 & $\begin{array}{l}\text { Amblyomma americanum (United } \\
\text { States) }\end{array}$ & I & + & + & - & - \\
\hline & 297 & Patient (United States) & I & + & + & - & - \\
\hline & GeHo & Patient (Germany) & I & + & + & - & - \\
\hline \multirow[t]{32}{*}{ B. garinii } & $20047^{\mathrm{T}}$ & Ixodes ricinus (France) & II & + & - & + & - \\
\hline & Ip90 & Ixodes persulcatus (Russia) & II & + & - & + & - \\
\hline & G1 & Patient (Germany) & II & + & - & + & - \\
\hline & $\mathrm{PBi}$ & Patient (Germany) & II & + & - & + & - \\
\hline & N34 & Ixodes ricinus (Germany) & II & + & - & + & - \\
\hline & Ir 210 & Ixodes ricinus (Russia) & II & + & - & + & - \\
\hline & HT17 & lxodes persulcatus (Japan) & II & + & - & + & - \\
\hline & HT32 & Ixodes persulcatus (Japan) & II & + & - & + & - \\
\hline & HT57 & Ixodes persulcatus (Japan) & II & + & - & + & - \\
\hline & HT59 & Lxodes persulcatus (Japan) & II & + & - & + & - \\
\hline & HT64 & Ixodes persulcatus (Japan) & II & + & - & + & - \\
\hline & HT72 & Ixodes persulcatus (Japan) & II & + & - & + & - \\
\hline & JEM4 & Patient (Japan) & II & + & - & + & - \\
\hline & HT37 & Ixodes persulcatus (Japan) & IV & + & - & + & - \\
\hline & JEM1 & Patient (Japan) & IV & + & - & + & - \\
\hline & JEM2 & Patient (Japan) & IV & + & - & + & - \\
\hline & JEM5 & Patient (Japan) & IV & + & - & + & - \\
\hline & JEM6 & Patient (Japan) & IV & + & - & + & - \\
\hline & JEM7 & Patient (Japan) & IV & + & - & + & - \\
\hline & JEM8 & Patient (Japan) & IV & + & - & + & - \\
\hline & FR146s & Apodemus argenteus (Japan) & IV & + & - & + & - \\
\hline & Asa5 & Apodemus speciosus (Japan) & IV & + & - & + & - \\
\hline & HT7 & Ixodes persulcatus (Japan) & IV & + & - & - & - \\
\hline & HT22 & lxodes persulcatus (Japan) & IV & + & - & - & - \\
\hline & NB100/1 & Ixodes persulcatus (Japan) & IV & + & - & - & - \\
\hline & HT19 & Ixodes persulcatus (Japan) & $\mathrm{V}$ & + & - & + & - \\
\hline & JEM3 & Patient (Japan) & V & + & - & + & - \\
\hline & FR502e & Apodemus speciosus (Japan) & $\mathrm{V}$ & + & - & + & - \\
\hline & HT55 & lxodes persulcatus (Japan) & VI & + & - & + & - \\
\hline & N411 & Ixodes persulcatus (Japan) & VI & + & - & + & - \\
\hline & N338 & Ixodes persulcatus (Japan) & VI & + & - & + & - \\
\hline & N337 & Ixodes persulcatus (Japan) & VI & + & - & - & - \\
\hline \multirow[t]{11}{*}{ B. afzelii } & $\mathrm{VS} 461^{\mathrm{T}}$ & Ixodes ricinus (Switzerland) & III & + & - & - & + \\
\hline & $\mathrm{BO} 23$ & Patient (Germany) & III & + & - & - & + \\
\hline & ACA1 & Patient (Sweden) & III & + & - & - & + \\
\hline & UMO1 & Patient (Sweden) & III & + & - & - & + \\
\hline & $\mathrm{KK} 2$ & Tick (nymph) (Korea) & III & + & - & - & + \\
\hline & Ip3 & Ixodes persulcatus (Russia) & III & + & - & - & + \\
\hline & HT61 & Lxodes persulcatus (Japan) & III & + & - & - & + \\
\hline & HT25 & Ixodes persulcatus (Japan) & III & + & - & - & + \\
\hline & HT10 & Ixodes persulcatus (Japan) & III & + & - & - & + \\
\hline & Asa1 & Apodemus speciosus (Japan) & III & + & - & - & + \\
\hline & FR478b & Apodemus speciosus (Japan) & III & + & - & - & + \\
\hline
\end{tabular}

hybridization probes as described previously $(11,17)$. The other experimental conditions used in the RFLP analysis have been described previously $(14,30)$.

PCR amplification. Total DNA was extracted and purified as described previously (9). PCR amplification with the primer sets specific for the $16 \mathrm{~S}$ rRNA gene of Borrelia species was carried out to identify the species. The following four PCR primer sets were prepared and used for species-specific DNA amplification experiments: primer set SC for conserved regions of the 16S rRNA gene $\left(5^{\prime}\right.$ GCT GGC AGT GCG TCT TAA G-3' and 5'-ATT CTT AGC TGC TGC CTC C-3'); primer set BB, which is specific for $B$. burgdorferi sensu stricto ( $5^{\prime}$-GGG ATG TAG CAA TAC ATT C-3' and 5'-ATA TAG TTT CCA ACA TAG G-3') primer set $\mathrm{BG}$, which is specific for $B$. garinii (5'-GGG ATG TAG CAA TAC ATC T-3' and 5'-ATA TAG TTT CCA ACA TAG T-3'); and primer set VS, which is specific for $B$. afzelii (5'-GCA TGC AAG TCA AAC GGA-3' and 5'-ATA TAG TTT CCA ACA TAG C-3'). All other experimental conditions were the same as the conditions described previously (9).
DNA-DNA hybridization. Levels of DNA reassociation were determined by the membrane filter hybridization method, as described previously $(16,25)$.

Flagellin gene amplification, cloning, and sequencing. The flagellin gene of $B$. burgdorferi sensu lato strains was amplified by PCR by using primers 5'-GAT TAT AAA TCA TAA TAG GTC AGC-3' and 5'-TTG AGG CAC TTG ATT TGC TTG TGC- $3^{\prime}$. The PCR was performed as described elsewhere (9), except that the annealing step $\left(45^{\circ} \mathrm{C}\right.$ for $\left.30 \mathrm{~s}\right)$ and the extension step $\left(72^{\circ} \mathrm{C}\right.$ for $\left.90 \mathrm{~s}\right)$ were modified. The PCR amplification product was then purified and ligated into vector pGEM5Zf by using the pGEM-T vector system (Promega, Madison, Wis.) as recommended by the manufacturer, as described previously (9). The recombinant DNA fragments were introduced into competent $E$. coli HB101 cells (Takara Shuzo Co., Ltd., Kyoto, Japan). The double-stranded plasmid DNA was extracted and purified as described previously (11). Sequencing reactions were primed with either vector-encoded primers UN (5'-CGA CGT CGC ATG CTC CCG GC-3') and RV (5'-CTC CCA TAT GGT CGA CCT GC-3') or custom- 


\section{$1223456789101112 \mathrm{M}$}

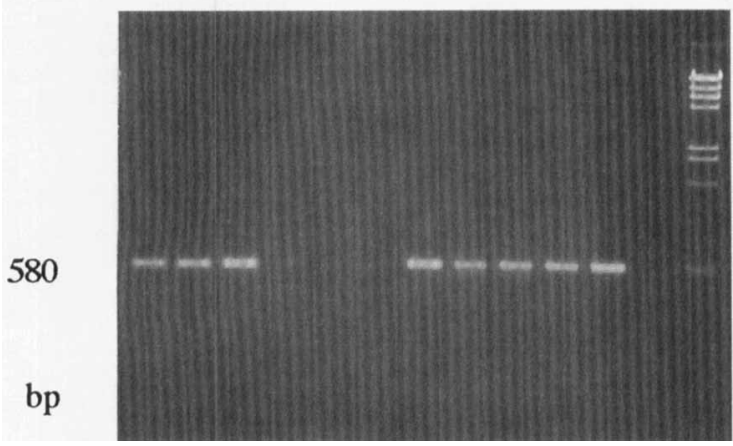

FIG. 1. PCR amplification with the $B$. garinii-specific primer set. The experimental conditions used have been described previously (14). The PCR-amplified DNA fragment size is shown on the left. Lane 1, strain HT37; lane 2, strain JEM5; lane 3, strain Asa5; lane 4, strain HT22; lane 5, strain HT7; lane 6, strain NB100/1; lane 7, strain HT19; lane 8, strain JEM3; lane 9, strain FR502e; lane 10, strain HT55; lane 11, strain N411; lane 12, strain N337; lane M, lambda DNA marker digested with HindIII and KpnI.

synthesized primers FLF1 (5'-TAA CGG CAC ATA CTC AGA TGC AGA CAG AGG-3'), FLF2 (5'-GGA TGA GGC AAT TGC TGT CAA TAT TTA TGC-3'), FLR1 (5'-GTC TAT TTT GGA AAG CAC CTA AAT TTG CTC-3'), and FLR2 (5'-GCA TTT GGT TGT ATT GAG CCT GAT C-3'). Sequence alignment, similarity matrix construction, and phylogenetic tree construction were performed with a Macintosh personal computer by using the DNASTAR program (DNASTAR, Inc., Madison, Wis.) and the CLUSTAL V software package (19).

Nucleotide sequence accession numbers. The flagellin gene nucleotide sequences of $B$. burgdorferi sensu lato isolates which we determined in this study have been assigned the following Genome Sequence Data Base, DNA Data Base of Japan, European Bioinformatics Institute, and National Center for Biotechnology Information accession numbers: D63363 (B. garinii HT17), D63364 (B. garinii JEM4), D63365 (B. afzelii VS461 ${ }^{\mathrm{T}}[\mathrm{T}=$ type strain]), D63366 (B. afzeli HT61), D63367 (ribotype group IV strain HT22), D63368 (ribotype group IV strain HT7), D63369 (ribotype group IV strain HT37), D63370 (ribotype group IV strain JEM5), D63371 (ribotype group V strain HT19), D63372 (ribotype group V strain JEM3), D63373 (ribotype group VI strain HT55), and D63374 (ribotype group VI strain N337). The accession numbers of the flagellin gene sequences of strains published previously $(18,23,34,36)$ that were compared in this study are as follows: $B$. burgdorferi sensu stricto type strain B31, X16833 strain GeHo, X56334; B. garinii Ip90, X75203; B. afzelii ACA1, X75202; Borrelia hermsii HS1, M33839; B. burgdorferi KL10, L42881; and B. burgdorferi NBSlab, L42876.

\section{RESULTS}

RFLP ribotyping analysis. The DNAs were digested with an enzyme, electrophoresed, blotted, and hybridized with $23 \mathrm{~S}$ rRNA gene probes. The RFLP ribotypes of spirochete isolates examined in this study and our previous studies are shown in Table 1.

PCR amplification analysis. Previous studies have revealed the usefulness of PCR amplification as a tool for the identification of the spirochetes associated with Lyme disease $(24,31$, $35)$. The results of our $16 \mathrm{~S}$ rRNA gene sequence-based PCR typing analysis in which the species-specific primer set was used confirmed the identities of ribotype group I, II, and III strains as members of $B$. burgdorferi sensu lato. The results of one such experiment are shown in Fig. 1, and the PCR amplification results are summarized in Table 1 . When we used primer set SC (primer sequence containing conserved regions of the $16 \mathrm{~S}$ rRNA gene), a fragment of the appropriate size (320 bp) was amplified from all of the DNA preparations tested in this study (data not shown). Figure 1 shows the results of an amplification experiment in which ribotype group IV, V, and VI isolates were tested for PCR amplification with primer set BG. Primer set $\mathrm{BG}$, which was specific for $B$. garinii, did not amplify DNAs from ribotype group IV isolates HT7, HT22, and NB100/1 and ribotype group VI strain N337 but did amplify DNA slightly when the annealing temperature was decreased from 52 to $50^{\circ} \mathrm{C}$. Primer set BG did amplify DNAs of the appropriately sized fragment $(580 \mathrm{bp})$ from the other ribotype group IV and $\mathrm{VI}$ isolates and all ribotype group V isolates.

DNA-DNA hybridization. To clarify the status of the ribotype groups, we determined the levels of DNA relatedness by performing DNA-DNA hybridization experiments. The relative binding ratios obtained in the hybridization experiments in which the membrane filter method was used are shown in Table 2. None of the isolates belonging to ribotype groups IV, $\mathrm{V}$, and VI were related to the type strains of $B$. burgdorferi and $B$. afzelii since the levels of DNA similarity ranged from 53 to $66 \%$. The ribotype group IV, V, and VI isolates were all related to strain 20047 , the type strain of B. garinii. The Japanese isolates were more closely related to each other than to European strain $20047^{\mathrm{T}}$. The ribotype group IV, V, and VI isolates were 77 to $88 \%$ related to each other and 70 to $80 \%$ related to the members of $B$. garinii.

Flagellin gene sequence alignment and phylogenetic analysis. The flagellin gene is a conserved gene which has been proven to be useful for identification of borreliae at the species level $(3,36)$. We cloned the flagellin gene of representatives of five ribotype groups, and the nucleotide sequences (985 of 1,011 bases) were determined in order to quantitatively assess the phylogenetic divergence of the strains belonging to other Borrelia species associated with Lyme disease. The flagellin sequences (937 bases without PCR primer sequences) of 18 borrelial strains were aligned and compared with the $B$. hermsii HS1 flagellin sequence as an outlier by using the DNASTAR program (DNASTAR, Inc.). The sequence of each isolate was determined with least two independent clones of a PCR product. When a nucleotide mismatch was detected, another clone was sequenced. A nucleotide discrepancy was observed about once per 2,000 bases under our experimental conditions, and the mismatches were thought to have resulted from $T a q$ enzyme synthesis errors.

The nucleotide sequence pair similarity values of the sequences were calculated by the Clustal method and are shown in Table 3. The similarity matrix showed that the levels of conservation of sequences and the degrees of sequence similarity ranged from 93.6 to $100 \%$ for all of the isolates associated with Lyme disease. The lowest levels of similarity ob-

TABLE 2. Levels of DNA relatedness among three Borrelia species and new ribotype group isolates

\begin{tabular}{|c|c|c|c|c|}
\hline \multirow{2}{*}{$\begin{array}{c}\text { Source of } \\
\text { unlabeled DNA }\end{array}$} & \multicolumn{4}{|c|}{$\begin{array}{l}\text { Relative binding ratios }(\%) \text { with the } \\
\text { following sources of labeled DNA: }\end{array}$} \\
\hline & $\begin{array}{l}\text { Strain } \\
20047^{\mathrm{T}}\end{array}$ & $\begin{array}{l}\text { Strain } \\
\text { HT37 }\end{array}$ & $\begin{array}{l}\text { Strain } \\
\text { HT19 }\end{array}$ & $\begin{array}{l}\text { Strain } \\
\text { HT55 }\end{array}$ \\
\hline B. burgdorferi $\mathrm{B} 31^{\mathrm{T}}$ & 56 & 56 & 53 & 53 \\
\hline B. garinii $20047^{\mathrm{T}}$ & 100 & 77 & 72 & 70 \\
\hline B. garinii HT17 & 77 & 78 & 73 & 78 \\
\hline B. garinii JEM4 & 74 & 79 & 80 & 80 \\
\hline $\begin{array}{l}\text { Borrelia sp. strain HT37 } \\
\text { (ribotype group IV) }\end{array}$ & 78 & 100 & 86 & 85 \\
\hline $\begin{array}{l}\text { Borrelia sp. strain JEM5 } \\
\text { (ribotype group IV) }\end{array}$ & 70 & 77 & 81 & 84 \\
\hline $\begin{array}{l}\text { Borrelia sp. strain HT19 } \\
\text { (ribotype group V) }\end{array}$ & 73 & 86 & 100 & 88 \\
\hline $\begin{array}{l}\text { Borrelia sp. strain HT55 } \\
\quad \text { (ribotype group VI) }\end{array}$ & 74 & 79 & 85 & 100 \\
\hline B. afzelii $\mathrm{VS} 461^{\mathrm{T}}$ & 66 & 54 & 57 & 58 \\
\hline
\end{tabular}


TABLE 3. Flagellin gene sequence similarity matrix for Borrelia isolates

\begin{tabular}{|c|c|c|c|c|c|c|c|c|c|c|c|c|c|c|c|c|c|c|c|}
\hline \multirow{2}{*}{ Strain } & \multicolumn{19}{|c|}{$\%$ Similarity } \\
\hline & HS1 & $\mathrm{B} 31^{\mathrm{T}}$ & GeHo & Ip90 & KL10 & NBSlab & HT17 & JEM4 & HT22 & HT7 & HT37 & JEM5 & HT19 & JEM3 & HT55 & N337 & $\mathrm{VS} 461^{\mathrm{T}}$ & HT61 & $\mathrm{ACA} 1$ \\
\hline B. hermsii HS1 & 100.0 & 83.1 & 83.2 & 83.0 & 82.9 & 82.9 & 83.0 & 82.8 & 82.7 & 82.5 & 82.6 & 82.4 & 82.6 & 82.6 & 82.3 & 82.7 & 83.1 & 83.1 & 83.0 \\
\hline B. burgdorferi $\mathrm{B} 31^{\mathrm{T}}$ & & 100.0 & 99.7 & 93.8 & 94.5 & 94.5 & 94.2 & 93.9 & 93.8 & 94.0 & 93.7 & 93.6 & 93.9 & 93.9 & 93.7 & 93.8 & 94.5 & 94.7 & 94.5 \\
\hline B. bungdorferi $\mathrm{GeHo}$ & & & 100.0 & 93.9 & 94.6 & 94.6 & 94.3 & 93.8 & 93.9 & 94.1 & 93.8 & 93.7 & 93.8 & 93.8 & 93.8 & 93.9 & 94.3 & 94.6 & 94.3 \\
\hline B. garinii Ip90 & & & & 100.0 & 98.7 & 98.7 & 99.0 & 99.1 & 98.8 & 98.7 & 98.5 & 98.4 & 98.6 & 98.6 & 98.7 & 98.7 & 95.1 & 94.9 & 95.4 \\
\hline Borrelia sp. strain KL10 & & & & & 100.0 & 100.0 & 99.0 & 98.7 & 98.7 & 98.8 & 98.3 & 98.3 & 98.5 & 98.5 & 98.6 & 98.6 & 95.1 & 95.0 & 95.1 \\
\hline Borrelia sp. strain NBSlab & & & & & & 100.0 & 99.0 & 98.7 & 98.7 & 98.8 & 98.3 & 98.3 & 98.5 & 98.5 & 98.6 & 98.6 & 95.1 & 95.0 & 95.1 \\
\hline B. garinii $\mathrm{HT} 17$ & & & & & & & 100.0 & 98.8 & 99.0 & 98.9 & 98.7 & 98.6 & 98.8 & 98.8 & 98.9 & 98.9 & 95.2 & 95.0 & 95.3 \\
\hline B. garinii JEM4 & & & & & & & & 100.0 & 98.8 & 98.9 & 98.5 & 98.4 & 98.8 & 98.8 & 98.7 & 98.7 & 95.5 & 95.3 & 95.4 \\
\hline HT22 (ribotype group IV) & & & & & & & & & 100.0 & 99.5 & 99.3 & 99.1 & 99.1 & 99.1 & 99.5 & 99.9 & 95.0 & 94.8 & 95.1 \\
\hline HT7 (ribotype group IV) & & & & & & & & & & 100.0 & 99.1 & 99.0 & 99.3 & 99.3 & 99.4 & 99.4 & 94.9 & 94.7 & 95.0 \\
\hline HT37 (ribotype group IV) & & & & & & & & & & & 100.0 & 98.8 & 98.8 & 98.8 & 99.1 & 99.1 & 94.7 & 94.5 & 94.8 \\
\hline JEM5 (ribotype group IV) & & & & & & & & & & & & 100.0 & 98.7 & 98.7 & 99.0 & 99.0 & 94.5 & 94.2 & 94.6 \\
\hline HT19 (ribotype group V) & & & & & & & & & & & & & 100.0 & 100.0 & 99.0 & 99.0 & 94.8 & 94.6 & 94.9 \\
\hline JEM3 (ribotype group V) & & & & & & & & & & & & & & 100.0 & 99.0 & 99.0 & 94.8 & 94.6 & 94.9 \\
\hline HT55 (ribotype group VI) & & & & & & & & & & & & & & & 100.0 & 99.4 & 94.9 & 94.7 & 95.0 \\
\hline N337 (ribotype group VI) & & & & & & & & & & & & & & & & 100.0 & 94.9 & 94.7 & 95.0 \\
\hline B. afzelii VS461 ${ }^{\mathrm{T}}$ & & & & & & & & & & & & & & & & & 100.0 & 99.6 & 99.6 \\
\hline B. afzelii HT61 & & & & & & & & & & & & & & & & & & 100.0 & 99.1 \\
\hline B. afzelii ACA1 & & & & & & & & & & & & & & & & & & & 100.0 \\
\hline
\end{tabular}

served were between ribotype group IV isolates HT37 and JEM5 and $B$. burgdorferi $\mathrm{B} 31^{\mathrm{T}}$. The flagellin sequences of strains HT19 and JEM3 were identical, as were the flagellin sequences of strains KL10 and NBSlab. The level of conservation of flagellin sequences between Japanese isolate HT61 and $B$. afzelii VS461 ${ }^{\mathrm{T}}$ was high, although the two isolates had different geographic origins.

A neighbor-joining phylogenetic tree (38) constructed on the basis of the data in the sequence similarity matrix is shown in Fig. 2. According to this tree, the Borrelia isolates associated with Lyme disease segregated into three clusters. The three different phylogenetic groups corresponded completely to the three $B$. burgdorferi sensu lato species. The most deeply branched group contained $B$. burgdorferi $\mathrm{GeHo}$ and $\mathrm{B} 31^{\mathrm{T}}$, and a second cluster consisted of $B$. afzelii VS461 ${ }^{\mathrm{T}}, \mathrm{HT} 61$, and

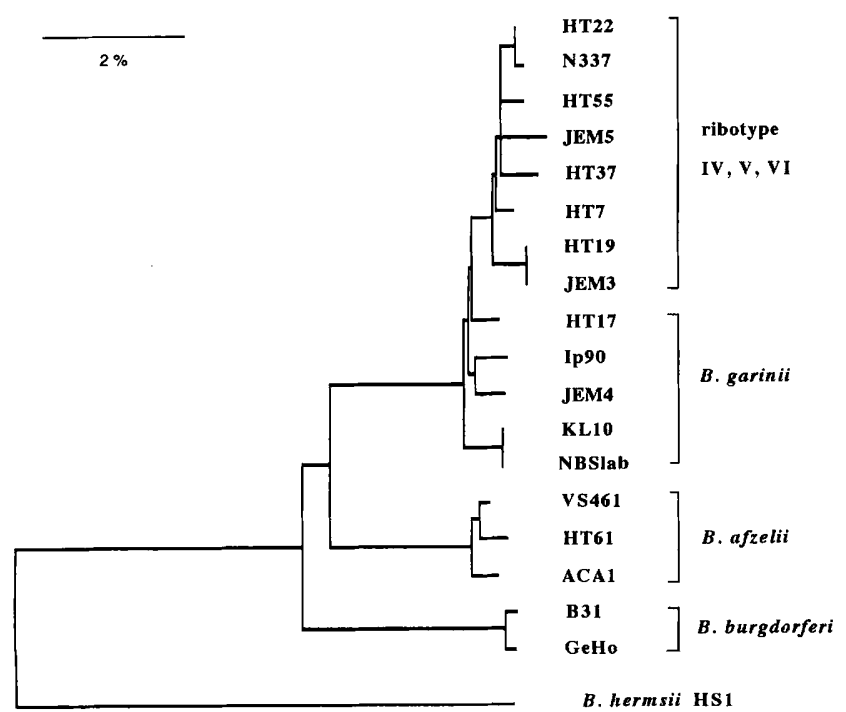

FIG. 2. Phylogenetic tree of Borrelia species isolates. The phylogenetic tree was constructed as described in the text by using nearly complete flagellin gene sequences. $\mathrm{Bar}=2 \%$ difference between sequences, as determined by measuring the length of the horizontal lines connecting two isolates.
ACA1. The third group comprised all ribotype group IV, V, and VI isolates and $B$. garinii isolates. Moreover, the isolates belonging to ribotype groups IV, V, and VI were closely related to each other. These isolates formed a subgroup that branched from the cluster consisting of $B$. garinii strains.

\section{DISCUSSION}

Our RFLP ribotyping system based on a unique organization was previously evaluated by using a large number of strains from North America, Europe, and Asia (12, 14, 30). Ribotype groups I, II, and III corresponded to $B$. burgdorfer sensu stricto, $B$. garinii, and $B$. afzelii, respectively. As determined by our typing method, both $B$. garinii and $B$. afzelii isolates were obtained from clinical specimens, $I$. persulcatus ticks, and reservoir rodents in Japan. However, many Japanese isolates produced unique RFLP patterns that were distinct from those of North American and European isolates. Therefore, we placed these organisms in groups designated ribotype groups IV to VI. $B$. garinii and the latter three ribotype groups could also be distinguished on the basis of their sodium dodecyl sulfate-polyacrylamide gel electrophoresis patterns, the results of Western blotting (immunoblotting) in which monoclonal antibodies specific to outer surface protein A were used, and the results of pulsed-field gel electrophoresis $(13,15,29)$. The results of a PCR amplification analysis in which we used primer sets $\mathrm{BB}, \mathrm{BG}$, and VS, which are specific for Borrelia species, confirmed the results of our RFLP ribotyping analysis.

The results of the PCR amplification analysis also demonstrated that the three new ribotype groups and $B$. garinii are more closely related to each other than $B$. burgdorferi or $B$. afzelii is to either of these groups, since the DNAs of some isolates classified as members of ribotype groups IV, V, and VI were amplified when the $B$. garinii-specific primer set was used. However, the results of PCR amplification experiments demonstrated that the primer positions of the 16S rRNA gene sequence substituted are in some ribotype group IV and VI isolates. The genetic similarity between $B$. garinii and ribotype groups IV to VI is also supported by the results of a recent report (9). We determined the OspC gene sequences of isolates, and the deduced amino acid sequence alignment clearly 
revealed that the $B$. garinii-specific sequence motif was fully conserved in all of the isolates belonging to ribotype groups IV, $\mathrm{V}$, and VI, while overall the OspC sequences were quite variable. However, the ribotype group IV, V, and VI isolates could not be assigned to a Borrelia species.

Our findings and other findings indicated that $B$. garinii is the most heterogeneous Borrelia species $(5,14,30,37,41,42)$. However, the levels of DNA relatedness between $B$. garinii and ribotype group IV, $\mathrm{V}$, and VI isolates were more than $70 \%$. Postic et al. (37) have reported that ribotype group IV strains Ip89 and NT29 exhibit high levels of DNA relatedness with the type strain of $B$. garinii. Whereas the ribotype group IV, $\mathrm{V}$, and VI isolates are more closely related to each other than to European type strain 20047, DNA-DNA hybridization results allowed us to conclude that all of the ribotype group IV to VI isolates belong to $B$. garinii. A phylogenetic analysis in which flagellin gene sequences were used clearly revealed that the representatives of ribotype groups IV to VI are all closely related to each other and belong to $B$. garinii. Interestingly, the phylogenetic tree showed that the cluster containing the ribotype group IV to VI isolates was slightly branched from the cluster containing typical $B$. garinii strains. This suggested that the ribotype group IV to VI isolates seem to have diverged from $B$. garinii. In this study, strains KL10 and NBSlab, which were previously classified in $B$. burgdorferi, were clearly assigned to $B$. garinii.

Most spirochete isolates classified as members of ribotype groups IV to VI were detected in I. persulcatus ticks collected in various localities of northern Japan, and ribotype group IV isolates were the predominant isolates in human infections in Japan $(12,27,33)$. It has been generally assumed that spirochetes are maintained in locations where Lyme disease is endemic by vector-reservoir transmission cycles involving ticks belonging to the Ixodes ricinus species complex $(6,7,20)$. Our previous results showed that there are some differences between the spirochetes isolated in Europe and the spirochetes isolated in Japan $(12,15,32)$. Therefore, our results showed that the ribotype group IV, V, and VI isolates confirmed the genomic diversity of $B$. garinii and are maintained in their own transmission cycle of spirochetes together with wildlife reservoirs. Our findings also suggest that the spirochetes classified as members of ribotype groups IV, V, and VI evolved within the framework of $B$. garinii and have adapted to Asiatic habitats and that there appeared to be sufficient ecological diversity that future bacterial speciation could occur. We have studied only a few European isolates; therefore, in the future we will investigate whether subtypes similar to ribotype groups IV to VI occur outside Japan.

\section{ACKNOWLEDGMENTS}

We deeply thank Guy Baranton (Institut Pasteur) for helpful discussions, useful comments, and strains, Bernard Hudson (Royal North Shore Hospital, Sydney, Australia) for critically reading the manuscript, and Sven Bergström (University of Umeå, Umeå, Sweden) for sending a manuscript prior to publication. We also thank R. C. Johnson (University of Minnesota) for strains of $B$. burgdorferi and to K. H. Park (Konkuku University, Chungdzu, Korea) for strain KK2. This work would not have been possible without the help, strains, and stimulating discussion supplied by Minoru Nakao and Kenji Miyamoto (Asahikawa Medical College of Japan). We also thank Masako Sohnaka, Akiko Hamase, Yoko Makita, Hiroko Makino, and Mie Yabuki for technical assistance.

This work was supported in part by Grants-in-Aid for Scientific Research 06044191, 06640912, and 07640939 from the Ministry of Education, Science and Culture of Japan and by a Takeda scientific research grant from the Takeda Science Foundation.

\section{REFERENCES}

1. Anderson, J. F. 1989. Epizootiology of Borrelia in Ixodes tick vectors and reservoir hosts. Rev. Infect. Dis. 11(Suppl. 6):s1451-s1459.

2. Anderson, J. F., P. H. Duray, and L. A. Magnarelli. 1987. Prevalence of Borrelia burgdorferi in white-footed mice and Ixodes dammini at Fort McCoy, Wis. J. Clin. Microbiol. 25:1495-1497.

3. Assous, M. V., D. Postic, G. Paul, P. Nevot, and G. Baranton. 1994. Individualisation of two new genomic groups among American Borrelia burgdorferi sensu lato strains. FEMS Microbiol. Lett. 121:93-98.

4. Baba, S., T. Hao, H. Fujita, K. Fujino, Y. Mizoguchi, K. Yoshikawa, H. Suzuki, I. C. Woo, N. Kubo, Y. Arashima, K. Kawano, and K. Iguchi. 1990. Lyme borreliosis---two subclinical cases. Rinsho Hifuka 44:483-486.

5. Baranton, G., D. Postic, I. Saint Girons, P. Boerlin, J. C. Piffaretti, M. Assous, and P. A. D. Grimont. 1992. Delineation of Borrelia burgdorferi sensu stricto, Borrelia garinii sp. nov., and group VS461 associated with Lyme borreliosis. Int. J. Syst. Bacteriol. 42:378-383.

6. Burgdorfer, W. 1984. Discovery of the Lyme disease spirochete and its relationship to tick vectors. Yale J. Biol. Med. 57:71-76.

7. Burgdorfer, W., S. F. Haynes, and D. Corwin. 1989. Pathophysiology of the Lyme disease spirochete, Borrelia burgdorferi, in ixodid ticks. Rev. Infect. Dis. 11(Suppl. 6):s1442-s1450.

8. Canica, M. M., F. Nato, L. du Merle, J. C. Mazie, G. Baranton, and D. Postic. 1993. Monoclonal antibodies for identification of Borrelia afzelii $\mathrm{sp}$ nov. associated with late cutaneous manifestations of Lyme borreliosis. Scand. J. Infect. Dis. 25:441-448.

9. Fukunaga, M., and A. Hamase. 1995. Outer surface protein C gene sequence analysis of Borrelia burgdorferi sensu lato isolates of Japan. J. Clin. Microbiol. 33:2415-2420.

10. Fukunaga, M., and I. Mifuchi. 1989. Unique organization of Leptospira interrogans rRNA genes. J. Bacteriol, 171:5763-5767.

11. Fukunaga, M., and M. Sohnaka. 1992. Tandem repeat of the $23 \mathrm{~S}$ and $5 \mathrm{~S}$ ribosomal RNA genes in Borrelia burgdorferi, the etiological agent of Lyme disease. Biochem. Biophys. Res. Commun. 183:952-957.

12. Fukunaga, M., M. Sohnaka, M. Nakao, and K. Miyamoto. 1993. Evaluation of genetic divergence of borrelial isolates from Lyme disease patients in Hokkaido, Japan, by rRNA gene probes. J. Clin. Microbio!. 31:2044-2048.

13. Fukunaga, M., M. Sohnaka, Y. Takahashi, M. Nakao, and K. Miyamoto. 1993. Antigenic and genetic characterization of Borrelia species isolated from Ixodes persulcatus in Hokkaido, Japan. J. Clin. Microbiol. 31:1388-1391.

14. Fukunaga, M., M. Sohnaka, and Y. Yanagihara. 1993. Analysis of Borrelia species associated with Lyme disease by rRNA gene restriction fragment length polymorphism. J. Gen. Microbiol. 139:1141-1146.

15. Fukunaga, M., and Y. Takahashi. 1994. Pulsed field gene electrophoresis analysis of Borrelia burgdorferi sensu lato isolated in Japan and taxonomic implications with Lyme disease spirochetes. Microbiol. Immunol. 38:747751.

16. Fukunaga, M., Y. Takahashi, Y. Tsuruta, O. Matsushita, D. Ralph, M. McClelland, and M. Nakao. 1995. Genetic and phenotypic analysis of Borrelia miyamotoi sp. nov., isolated from the ixodid tick Ixodes persulcatus, the vector for Lyme disease in Japan. Int. J. Syst. Bacteriol. 45:804-810.

17. Fukunaga, M., Y. Yanagihara, and M. Sohnaka. 1992. The 23S/5S ribosomal RNA genes ( $r l / r r f)$ are separate from the 16S ribosomal RNA gene ( $r s)$ in Borrelia burgdorferi, the aetiological agent of Lyme disease. J. Gen. Microbiol. 138:871-877.

18. Gassmann, G. S., E. Jacobs, R. Deutzmann, and U. B. Göbel. 1991. Analysis of the Borrelia burgdorferi GeHo fla gene and antigenic characterization of its gene product. J. Bacteriol. 173:1452-1459.

19. Higgines, D. G., A. J. Bleasby, and R. Fuchs. 1992. CLUSTAL V: improved software for multiple sequence alignment. Comput. Appl. Biosci. 8:189-191.

20. Jaenson, T. G. T. 1991. The epidemiology of Lyme borreliosis. Parasitol. Today $7: 39-45$

21. Johnson, R. C., F. W. Hyde, G. P. Schmid, and D. J. Brenner. 1984. Borrelia burgdorferi sp. nov.: etiological agent of Lyme disease. Int. J. Syst. Bacteriol. 34:496-497.

22. Kawabata, M., S. Baba, K. Iguchi, N. Yamaguchi, and H. Russell. 1987. Lyme disease in Japan and its possible incriminated tick vector, Ixodes persulcatus. J. Infect. Dis. 156:854.

23. Livey, I., C. P. Gibbs, R. Schuster, and F. Dorner. 1995. Evidence for lateral transfer and recombination in OspC variation in Lyme disease borrelia. Mol. Microbiol. 18:257-269.

24. Marconi, R. T., and C. F. Garon. 1992. Development of polymerase chain reaction primer sets for diagnosis of Lyme disease and for species-specific identification of Lyme disease isolates by 16S rRNA signature nucleotide analysis. J. Clin. Microbiol. 30:2830-2834.

25. Meyer, S. A., and K. H. Scleifer, 1978. Deoxyribonucleic acid reassociation in the classification of coagulase positive staphylococci. Arch. Microbiol. 117: 183-188.

26. Miyamoto, K., M. Nakao, N. Sato, and M. Mori. 1991. Isolation of Lyme disease spirochetes from an ixodid tick in Hokkaido, Japan. Acta Trop. 49: $65-68$.

27. Miyamoto, K., M. Nakao, K. Uchikawa, and H. Fujita. 1992. Prevalence of Lyme borreliosis spirochetes in ixodid ticks of Japan, with special reference 
to a new potential vector, Ixodes ovatus (Acari: Ixodidae). J. Med. Entomol. 29:216-220.

28. Miyamoto, K., K. Takahashi, N. Sato, K. Uraguchi, K. Matsuo, J. Iizuka, M. Mori, Y. Tsuboi, and K. Ohtsuka. 1990. Cases of erythema and Lyme disease associated with tick-bite in Hokkaido. Jpn. J. Sanit. Zool. 41:63-65.

29. Nakao, M., and K. Miyamoto. 1993. Reservoir competence of the wood mouse, Apodemus speciosus ainu, for the Lyme disease spirochete, Borrelia burgdorferi, in Hokkaido, Japan. Jpn. J. Sanit. Zool. 44:69-84.

30. Nakao, M., K. Miyamoto, and M. Fukunaga. 1994. Lyme disease spirochetes in Japan: enzootic transmission cycles in birds, rodents, and Ixodes persulcatus ticks. J. Infect. Dis. 170:878-882.

31. Nakao, M., K. Miyamoto, M. Fukunaga, Y. Hashimoto, and H. Takahashi. 1994. Comparative studies on Borrelia afzelii isolated from a patient of Lyme disease, Ixodes persulcatus ticks, and Apodemus speciosus rodents in Japan. Microbiol. Immunol. 38:413-420.

32. Nakao, M., K. Miyamoto, N. Kawaguchi, Y. Hashimoto, and H. Iizuka. 1992. Comparison of Borrelia burgdorferi isolated from humans and ixodid ticks in Hokkaido, Japan. Microbiol. Immunol. 36:1189-1193.

33. Nakao, M., K. Miyamoto, K. Uchikawa, and H. Fujita. 1992. Characterization of Borrelia burgdorferi isolated from Ixodes persulcatus and Ixodes ovatus ticks in Japan. Am. J. Trop. Med. Hyg. 47:505-511.

34. Noppa, L., N. Burman, A. Sadziene, A. G. Barbour, and S. Bergström. 1995. Expression of the flagellin gene in Borrelia is controlled by an alternative $\rho$ factor. Microbiology 141:85-93.

35. Park, K. H., W. H. Chang, and T. G. Schwan. 1993. Identification and characterization of Lyme disease spirochetes, Borrelia burgdorferi sensu lato, isolated in Korea. J. Clin. Microbiol. 31:1831-1837.

36. Picken, R. N. 1992. Polymerase chain reaction primers and probes derived from flagellin gene sequences for specific detection of the agents of Lyme disease and North American relapsing fever. J. Clin. Microbiol. 30:99-114.

37. Postic, D., M. V. Assous, P. A. D. Grimont, and G. Baranton. 1994. Diversity of Borrelia burgdorferi sensu lato evidenced by restriction fragment length polymorphism of $m f(5 S)-r r l$ (23S) intergenic spacer amplicons. Int. J. Syst. Bacteriol. 44:743-752.

38. Saitou, N., and M. Nei. 1987. The neighbor-joining method: a new method for reconstructing phylogenetic trees. Mol. Biol. Evol. 4:406-425.

39. Southern, E. M. 1975. Detection of specific sequence among DNA fragments separated by gel electrophoresis. J. Mol. Biol. 98:503-517.

40. Takahashi, Y., M. Sohnaka, M. Nakao, K. Miyamoto, and M. Fukunaga. 1993. Characterization of Borrelia species isolated from ixodid ticks, Ixodes ovatus. Microbiol. Immunol. 37:721-727.

41. Wallich, R., C. Helmes, U. E. Schaible, Y. Lobet, S. E. Moter, M. D. Kramer, and M. M. Simon. 1992. Evaluation of genetic divergence among Borrelia burgdorferi isolates by use of OspA, $f l a$, HSP60, and HSP70 gene probes. Infect. Immun. 60:4856-4866.

42. Wilske, B., V. Preac-Mursic, U. B. Göbel, B. Graf, S. Jauris, E. Soutschek, E. Schwab, and G. Zumstein. 1993. An OspA serotyping system for Borrelia burgdorferi based on reactivity with monoclonal antibodies and OspA sequence analysis. J. Clin. Microbiol. 31:340-350. 